\title{
Assessment of the Role of Noni (Morinda citrifolia) Juice for Inducing Osteoblast Differentiation in Isolated Rat Bone Marrow Derived Mesenchymal Stem Cells
}

\author{
Sharmila Hussain ${ }^{1}$, Ramasamy Tamizhselvi ${ }^{2}$, Leema George ${ }^{2}$, Venkatraman Manickam² \\ ${ }^{1}$ Dental Sciences, Bharat University, Madha Dental College and Hospital, Dr.MGR Medical University, Chennai, \\ ${ }^{2}$ School of BioSciences and Technology, Vellore Institute of Technology, VIT University, Vellore, Tamilnadu, India
}

\begin{abstract}
Background and Objectives: Morinda citrifolia (Noni), an important traditional medicinal plant still used in patients with bone fractures or dislocation to promote connective tissue repair and to reduce inflammation. However, the effects of Noni on bone metabolism and whether it influences the osteogenic differentiation is yet to be clarified. In this study, we investigated the effect of Morinda citrifolia (Noni) juice on the proliferation rate of rat bone marrow derived mesenchymal stem cells (BMSC) and the osteoblastic differentiation as shown by alkaline phosphatase (ALP), Runt-related transcription factor 2 (Runx2) and osteocalcin (OCN) mRNA expression in vitro.

Methods and Results: Treatment with $200 \mu \mathrm{g} / \mathrm{ml}$ Noni juice enhanced the proliferation rate of the BMSC and also upregulated the osteogenic differentiation marker genes ALP and OCN, and Runx2 measured by RTPCR. Consistent with these results collagen scaffolds implanted in vivo, which were loaded with BMSC pre-exposed to Noni, showed increased bone density measured by computed tomography and histological analysis revealed neo-angiogenesis for bone formation.

Conclusions: These results suggest that Noni stimulates osteoblastogenesis and can be used as adjuvant natural medicine for bone diseases such as osteoporosis.
\end{abstract}

Keywords: Bone marrow derived mesenchymal stem cells, Morinda citrifolia, Alkaline phosphatase, Runt-related transcription factor 2, Osteocalcin

\section{Introduction}

The global incidence of age-related diseases of bone, joint, and muscle is steadily rising, seriously affecting the health of millions of people across the world. According

\footnotetext{
Accepted for publication July 20, 2016, Published online November 30, 2016 Correspondence to Ramasamy Tamizhselvi

School of BioSciences and Technology, Vellore Institute of Technology, VIT University, Vellore 632014, Tamilnadu, India Tel: +91-0416-2202949, Fax: +91-416-2243092

E-mail: tamizhselvi.r@vit.ac.in

(c) This is an open-access article distributed under the terms of the Creative Commons Attribution Non-Commercial License (http://creativecommons.org/ licenses/by-nc/4.0/), which permits unrestricted non-commercial use, distribution, and reproduction in any medium, provided the original work is properly cited.
}

to the United Nations (UN) (1) and the World Health Organization (WHO) (2) musculoskeletal, rheumatic, and arthritic conditions are leading causes of morbidity and disability throughout the world, and result in enormous healthcare expenditure and loss of work (3).

Maintenance of healthy bone requires bone remodelling, governed by the interactions between osteocytes, osteoblasts and osteoclasts (4). Osteoblasts are specialised bone forming cells that derive from local mesenchymal progenitors through multi-step commitment and maturation processes that are mainly mediated through the transcription factor Runx2 (5). It is often referred as the master switch of osteogenic differentiation. Thus Runx2 is crucial for the generation of a mineralized tissue (6) and it is expressed during the early phases of osteogenic differentiation. The 
role of Runx2 on regulating bone phenotypic genes was demonstrated that Runx2 can upregulate the expression of osteocalcin $(\mathrm{OCN})$, and also modulates other genes, such as alkaline phosphatase (ALP) $(7,8)$. ALP is the major organic component of bone extracellular matrix produced by osteoblasts (9). Both the mRNA and protein expression of ALP can be used to describe osteogenic differentiation progression. Furthermore, the constituent of the bone extracellular matrix, OCN, is also used as early marker of osteogenic differentiation and mineralization (10).

Morinda citrifolia, also known as Noni or Indian mulberry, an important traditional medicinal plant commonly used in treating the patients with bone fractures or dislocation to promote connective tissue repair and to reduce inflammation (11). A number of major components essential for its medicinal property have been identified in the Noni plant (12-15). The antioxidant activity of Noni is due to polyphenols, anthraquinones, $\alpha$-tocopherol and carotene. In cancer cells, phenolics, alkaloids, damnacanthal and flavonoids promote antioxidants (16). The fruit juice is in high demand in alternative medicine for different kinds for illnesses such as arthritis, diabetes, AIDS, gastric ulcer, mental depression, and arteriosclerosis. Several studies have also demonstrated anti-inflammatory, antioxidant and apoptosis-inducing effects of Noni in various cancers (17). Although different uses of noni have been investigated, the bone-healing properties have not been studied. In the present work, we first investigated the effect of noni juice on the osteogenic gene expression of Runx2, ALP and OCN in in vitro differentiation of BMSC; we then investigated whether Noni increases the bone regenerative effect of BMSC in vivo.

\section{Materials and Methods}

\section{Isolation and culture of BMSC}

All experimental protocols were reviewed and approved by the by CPCSEA (Committee for the Purpose of Control and Supervision on Experiments on Animals) and the Institutional Animal Ethics Committee (Approval no.VIT/IEAC $/ 9^{\text {th }} / J$ uly $26^{\text {th }} /$ No.26). The femur and tibia from male Wistar rats $(80 \sim 100 \mathrm{gm})$ were excised and bone marrow cells were slowly flushed out from the marrow cavity using DMEM (Life Technologies) prior to seeding into a $75 \mathrm{~cm}^{2}$ culture flask containing DMEM with $10 \%$ inactivated FBS 2 mM L-glutamine, $100 \mathrm{U} / \mathrm{ml}$ penicillin and streptomycin at $37^{\circ} \mathrm{C}$ in a humidified tissue culture incubator containing $5 \% \mathrm{CO}_{2}$ and $95 \%$ air. Non-adherent cells were removed after $24 \mathrm{~h}$. Cultured rat BMSC were observed under an inverted microscope.

\section{Noni Juice}

The Noni Juice or original Divine noni Gold (Noni Biotech Private Ltd, India) was utilized in this study as it supplies the noni fruit as a puree with no chemical fillers, thickeners, or preservatives (18).

\section{MTT Cell Viability Assay}

Cell viability of BMSC with or without Noni treatment was assessed via the MTT (3-(4, 5-dimethylthiazol-2-yl)-2, 5-diphenylte-trazolium bromide) assay (Sigma Aldrich), which measures the ability of cells to reduce MTT to formazan. After acid isopropanol extraction, formazan absorbance was quantified at $570 \mathrm{~nm}$ with a reference wavelength of $630 \mathrm{~nm}$ (ELx-800 biotek absorbance reader).

\section{Determining the growth curve}

The BMSC were seeded into well plates at a density of $5000 \mathrm{cells} /$ well. Cell counts were carried out at days 2, 3, 4, 5 and 6 after seeding. Cells from 3 wells were used to determine each cell count and mean values were used to determine the growth curve.

\section{Induction of osteogenic differentiation}

The femur and tibia from a male Wistar rat $(80 \sim 100$ gm) were excised and bone marrow cells were slowly flushed out from the marrow cavity using DMEM (Life technologies) prior to seeding into a $75 \mathrm{~cm}^{2}$ culture flask containing DMEM with $10 \%$ inactivated FBS, $0.1 \mu \mathrm{M}$ dexamethasone (Sigma Aldrich), $10 \mathrm{mM} \beta$-glycerophosphate (Sigma Aldrich), $50 \mathrm{mg} / \mathrm{ml}$ L-ascorbic acid (Sigma Aldrich) and with or without Noni $(200 \mu \mathrm{g})$. Cells were then incubated at $37^{\circ} \mathrm{C}$ in a humidified tissue culture incubator containing $5 \% \mathrm{CO}_{2}$ and $95 \%$ air. The medium was replaced every 3 days. On day 7 cells were collected for RT-PCR analysis. Triplicate tests were conducted in each experiment.

\section{RNA Extraction and RT-PCR Analysis}

Semiquantitative Polymerase Chain Reaction: For reverse transcription polymerase chain reaction (RT-PCR) analysis, total RNA was extracted from the cells using TRIzol reagent (Sigma Aldrich) following the manufacturer's instructions with some modifications and quantitated by spectrophotometric measurement of absorbance at $260 \mathrm{~nm}$ and analyzed on a $1 \%$ agarose gel for quality. Total RNA was reverse transcribed into cDNA with verso cDNA Synthesis Kit (Thermo scientific) according to the manufacturer's recommendations. The expression of ALP, OCN and Runx2 were analysed by standard PCR, using $2 \mu 1$ of cDNA per reaction. Primers for ALP, OCN and 
Runx2 were synthesized by sigma Aldrich. The primers used are as follows: ALP 5'-AACGTGGCCAAGAACATCATCA-3', 5'-TGTCCATCTCCAGCCGTGTC-3', osteocalcin 5'-AAAGCCCAGCGACTCT-3', 5'-CTAAACGGTGGTGCCATAGAT-3'; r Runx2, 5'-GCTTCTCCAACCCACGAATG-3', 5'-GAACTGATAGGACGCTGACGA-3', GAPDH forward, 5'-TATGACTCTACCCACGGCAA-3' and reverse, 5'-ATACTCAGCACCAGCATCACC-3'. Total RNA was reverse transcribed into cDNA with verso cDNA Synthesis Kit (Bio-Rad Laboratories). The PCR protocol consisted of optimized 38 cycles of denaturation at $95^{\circ} \mathrm{C}$ for 30 seconds, annealing for 30 seconds at $58^{\circ} \mathrm{C}$, and extension at $72^{\circ} \mathrm{C}$ for 30 seconds performed in MyCycler (Bio-Rad Laboratories). The amplified products were resolved by electrophoresis in $1.5 \%$ agarose gels and visualized by gel-red staining and photographed using Gel Doc-It Imaging System. GAPDH was used as an internal control to normalize the signal from genes of interest.

Real-time PCR: Total RNA was purified from cells by TRIzol extraction. A total of 100 ng of RNA was used for each real-time PCR. It was amplified by Light Cycler real time PCR machine (Bio-Rad) using SYBR green I master mix (Sigma). Gene expression was calculated relative to GAPDH levels by the comparative $\triangle \mathrm{CT}$ values method.

Loading of Scaffolds with Cells: The type I collagen scaffolds $(5 \mathrm{~mm} \times 5 \mathrm{~mm})$ were incubated with $3 \mathrm{ml}$ BMSC expanded in monolayer culture (treated with or without Noni), containing $5 \times 10^{6}$ cells on a roller for 1.5 hours. Then, the scaffolds were put into a sterile 6-well plate and the cell suspension was centrifuged at $470 \times \mathrm{g}$ for $5 \mathrm{~min}$ to recover the remaining BMSCs. The cell pellet was resuspended in $70 \mu \mathrm{l}$ culture medium and pipetted onto the scaffolds immediately before transplantation (19). To evaluate the seeding efficiency the cells that did not adhere to the scaffold were counted on the culture dish on day 1 after harvesting the scaffold. To assess cell penetration into the collagen, representative slices of the upper, the lower (200 $\mu \mathrm{m}$ below the surface) and the middle of the scaffold were selected for evaluation. These slices were randomly examined with regard to the number of cells per view field in a $10 \mathrm{X}$ magnification. The average cell number of 3 random fields was calculated. A seeding efficacy of more than $85 \%$ for both scaffolds was measured with this technique (20).

Transplantation of the scaffold loaded with BMSC pre-exposed to Noni into bone defects of rat: All animals will be cared according to the policies and principles established by the VIT University ethical clearance for animal study. Six to three-month-old male Wistar rats (250 $300 \mathrm{gm}$ ) were evenly divided into two groups of five each: (a) BMSC and (b) BMSC with noni. Animals were anesthetized with a combination of i.p. ketamine $(140 \mathrm{mg} / \mathrm{kg}$ of body weight) and i.p. xylazine $(7 \mathrm{mg} / \mathrm{kg}$ of body weight). Midline incisions approximately $1 \mathrm{~cm}$ in length were made on the femur. An incision was made on the ventral surface of the rat femur. The collagen scaffolds which have been cultured with BMSC (treated with or without noni) were implanted into the defect. The ablated periosteum and skin were repositioned and sutured respectively. The animals were sacrificed after 6weeks postoperatively and femur was harvested. The tissues were immersed in 4\% paraformaldehyde in $0.1 \mathrm{M}$ PBS ( $\mathrm{pH} 7.4$ ) for the tissue fixation and kept overnight at $4^{\circ} \mathrm{C}$.

Computed Tomography: For femur healing, a computed tomographic evaluation was obtained after 6 weeks. One millimeter coronal sections of defect regions were obtained 6 weeks after surgery. These defects were outlined using the Image J program. The outline of 1-mm coronal sections of the alveolar defect was used to determine the preoperative defect, postoperative defect, and volume of bone fill obtained by Image Pro software.

Histology Staining: The tissues will be fixed with $4 \%$ phosphate-buffered formalin freshly prepared from Para formaldehyde. After an overnight fixation at $4^{\circ} \mathrm{C}$, the tissues were suspended in phosphate-buffered saline. The specimens will be completely demineralised in buffered $10 \%$ EDTA prior to embedding, whereas the remainder is to be left mineralized for decalcification processing. The decalcified tissues will be embedded in paraffin so that

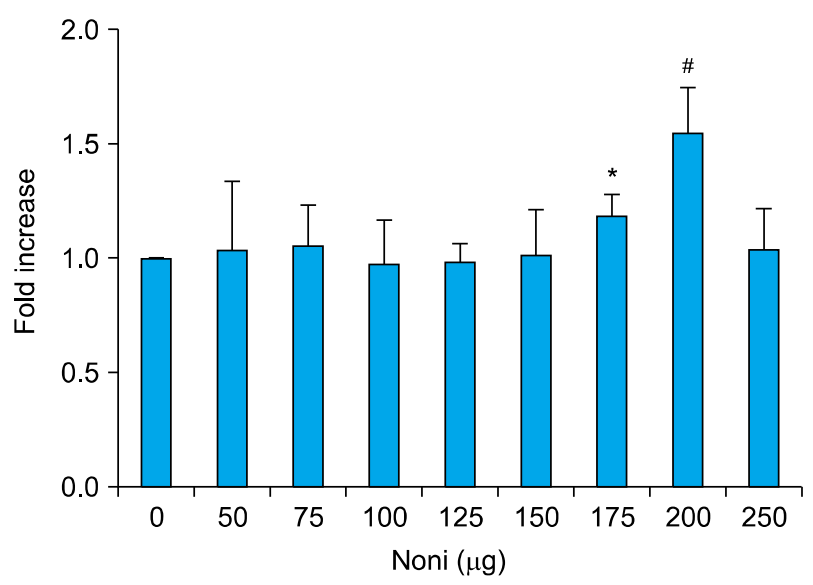

Fig. 1. Rat BMSC where cultured with varying doses of Noni (50, $75,100,125,150,175,200$ and $250 \mu \mathrm{g} / \mathrm{ml})$ for $24 \mathrm{~h}$. Noni at a concentration of $200 \mu \mathrm{g} / \mathrm{ml}$ significantly increased the proliferation of BMSC. MTT assay was performed to measure the cell proliferation as described in Materials and Methods. The data are mean $\pm S D, n=6 .{ }^{*} p<0.01$ and ${ }^{*} p<0.001$ as compared with BMSC (BMSC-bone marrow derived mesenchymal stem cells). 
their largest cut surfaces were sectioned; the sections were deparaffinised, hydrated, and stained with hematoxylin and eosin. Separate unstained slides, incorporating 5$\mu \mathrm{m}$-thick sections, were prepared for in-situ hybridization, described below. The undecalcified tissues were dehydrated in ethanol and embedded in methyl methacrylate; $5-\mu \mathrm{m}$-thick sections were obtained and stained with Goldner's modified trichrome or left to be unstained.

Statistical Analysis: Data are expressed as the mean \pm standard deviation (SD). In all figures, vertical error bars denote the SD. The significance of changes was evaluated by analysis of variance (ANOVA), with student's t- test when comparing two groups. A p-value of less than 0.05 was considered statistically significant.
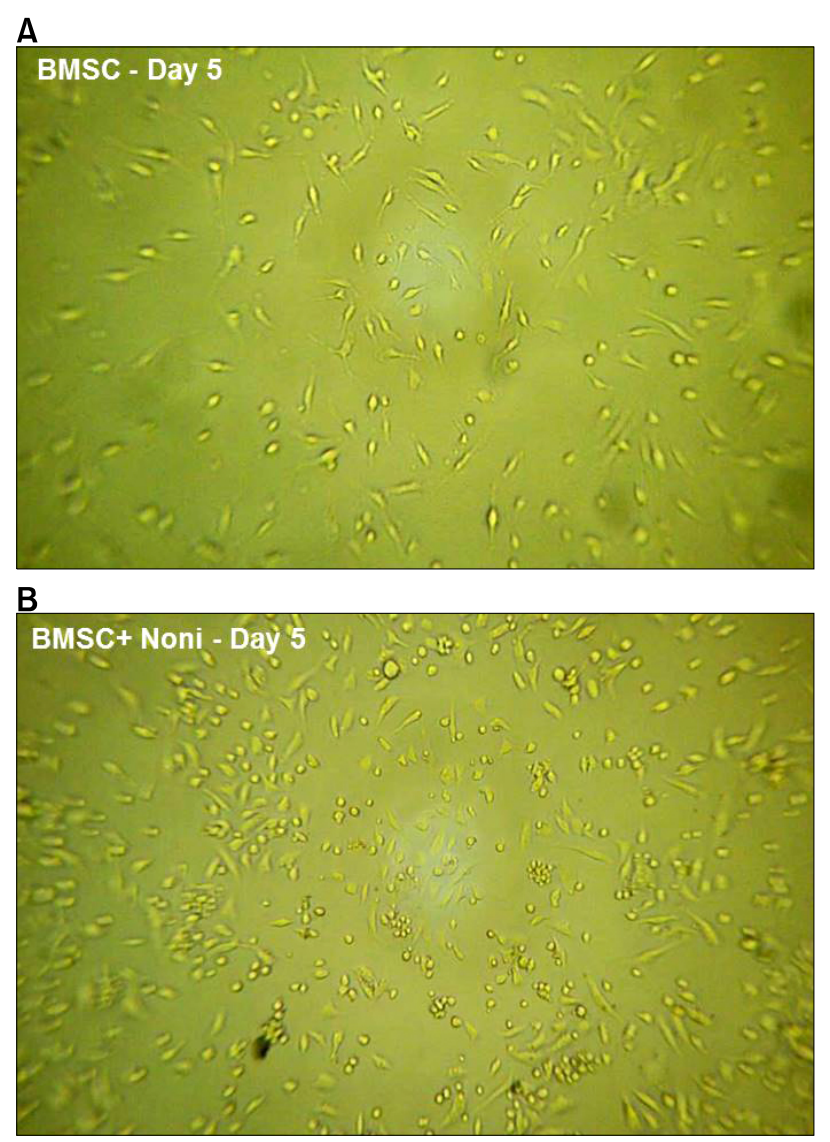

\section{Results}

Mesenchymal stem cells have been considered to be an ideal source of stem cells for regenerative medicine and transplantation therapy. The initial culture of the isolated MSCs contained a heterogeneous population of cells with both round and fibroblastic cells till 5th day of isolation after which the cells attained typical fibroblastic morphology and confluency with time. When checked for BMSC markers, the isolated cells showed positive expression of CD90 and CD44 genes (Fig. 2A-C).

\section{Effect of Noni on the proliferation of BMSC}

We determined the effect of Noni on proliferation of BMSC by MTT assay. As shown in Fig. 1, BMSC were exposed to various concentrations of Noni (50, 75, 100,

C

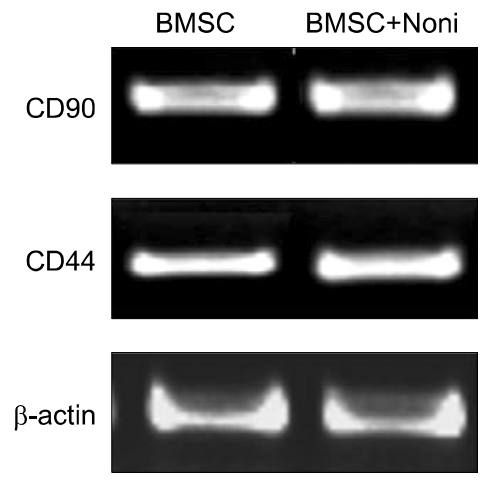

D

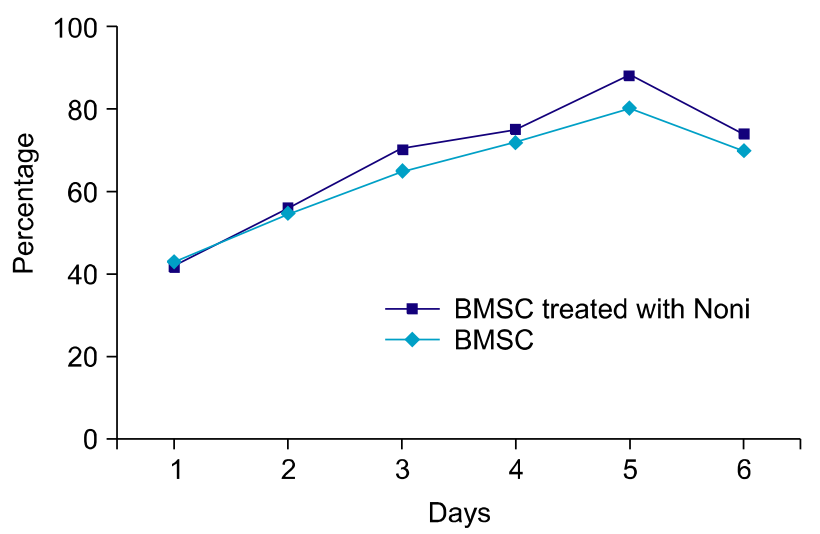

Fig. 2. Effect of Noni $(200 \mu \mathrm{g} / \mathrm{ml})$ on rat bone marrow derived stem cells after 5 days and before inducing with osteogenesis media. Morphology of cells (A) without and with (B) Noni on the fifth day $(40 \times$ objectives). (C) Transcriptional analysis for the expression of mesenchymal stem cell marker genes CD 44 and CD 90 generated from 5 independent experiments that were normalized with $\beta$ actin. (D) Growth curve of rat BMSC through 6 days. At day 1, 2, 3, 4, 5, 6 first passage BMSCs in DMEM with or without noni were plated in each well of a 96-well plate; cell number was then evaluated at different times via Thiazolyl blue (MTT) staining. Noni at a concentration of $200 \mu \mathrm{g} / \mathrm{ml}$ showed a significant increase in BMSC proliferation from $2^{\text {nd }}$ through $5^{\text {th }}$ day. MTT results are reported as percentages (BMSC-bone marrow derived mesenchymal stem cells). 
$125,150,175,200,250 \mu \mathrm{g})$ for $48 \mathrm{~h}$. As compared to control group (cells without Noni treatment) Noni significantly increased the cell viability by $117.93 \%(\mathrm{p}<0.05)$ and $154.61 \%(\mathrm{p}<0.01)$ at 175 and $200 \mu \mathrm{g} / \mathrm{ml}$ respectively. But with subsequent increase in concentration the proliferation dropped. At a concentration of $250 \mu \mathrm{g} / \mathrm{ml}$ it was $102 \%$ when compared with control group (100\%). No dose dependent effect of Noni on BMSC could be observed. 200 $\mu \mathrm{g} / \mathrm{ml}$ Noni increased cell viability by about 0.5 fold (Fig. 1). Thus, $200 \mu \mathrm{g} / \mathrm{ml}$ Noni was chosen for further experiments with BMSC.

\section{Growth curve of BMSCs}

Fig. 2D shows the growth curve of original passage BMSC with and without Noni treatment. On day 1, cells were in the latent period; on days $2 \sim 4$, cell proliferation accelerated; on day 5, cell growth was maximum (cell density reached $70 \sim 80 \%$ confluency) and on day 6 cell growth gradually decelerated and began to decline. $24 \mathrm{~h}$ after cell seeding, a small number of cells were observed growing on the flask surface with extensions stretched out. Other cells with around, bright appearance, in absence of adhesion to the surface, were also observed. With increased culture time, cells gradually stretched to become more elongated and the colony quantity increased. On day 3 of culture, the density of elongated cells and cell colony number was further increased. By day 5 of culture, the cell volume was expanded, colonies were linked and confluence was about 70\% 85\%. The concentration $200 \mu$ $\mathrm{g} / \mathrm{ml}$ of Noni enhanced the cell proliferation, moreover Noni showed a more dense appearance with increased number of cells (88\% on day 5) (Fig. 2B) as compared to control (75\% on day 5) (Fig. 2A).

\section{Expression patterns of osteoblast differentiation maker genes in response to Noni}

To evaluate the effects of Noni on osteoblast differentiation, we evaluated whether Noni induced osteogenic commitment of BMSC by controlling the transcriptional program. Using real time PCR analysis, the master osteo-lineage transcription factor Runx2 and its downstream target gene OCN and ALP were analysed. As cleared from results (Fig. 3A and B), $200 \mu \mathrm{g} / \mathrm{ml}$ of Noni significantly elevated the Runx2, ALP and OCN by 0.4 fold expression in BMSC as compared to non-treated control cells $(p<0.05)$. All the experiments were repeated at least three times and showed similar effects. Expression ALP described the early cell differentiation of osteoblastic cells (21). As observed from numerical data (Fig. 3B), $200 \mu \mathrm{g} / \mathrm{ml}$ of Noni induced ALP level by 0.5 fold $(\mathrm{p}<0.05)$ significantly as compared to control. The mRNA expression of Runx2 (0.3 fold) and OCN (0.4 fold) also showed significant ( 0.3 fold; $\mathrm{p}<0.05)$ increase with addition of $200 \mu \mathrm{g} / \mathrm{ml}$ of Noni.

\section{Noni treated BMSC Led to Vascularization and bone formation than BMSC Alone}

We then sought to investigate whether Noni would have any effect in the ability of BMSC to enhance bone formation in the femur of rat. Loading collagen scaffolds with BMSC exposed to Noni lead to neo-vascularization (Fig. 4A) as compared to BMSC alone loaded controls which showed normal bone healing with single harvesian
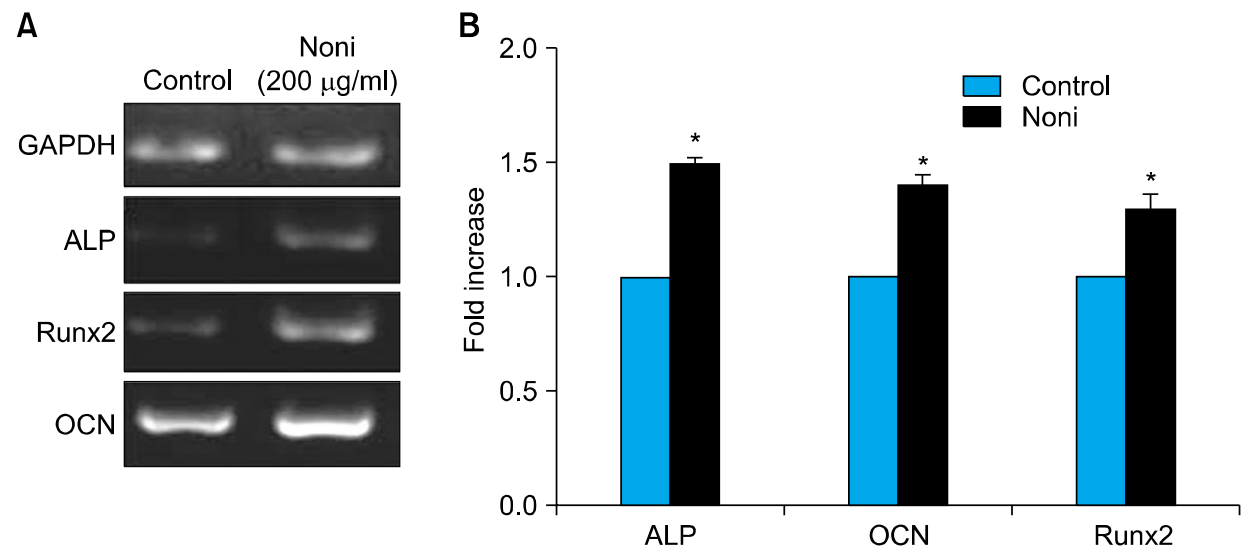

Fig. 3. Transcriptional analysis for the expression of osteogenic marker genes in bone marrow derived stem cells after 7 days of differentiation in the presence of Noni $(200 \mu \mathrm{g} / \mathrm{ml})$. (A) Semiquantitative RT-PCR detection of ALP, runx2 and OCN mRNA expression in cells treated with and without Noni. Sample loading was normalized with GAPDH internal control. (B) A significant increase in ALP, Runx2 and OCN was observed by real-time analysis. The data are mean \pm SD. Results of 3 to 5 experiments are shown. ${ }^{*} p<0.01$ when compared with BMSC (BMSC-bone marrow derived mesenchymal stem cells). 
system (Fig. 4B).

CT scan confirmed the influence of BMSC exposed to Noni on the bone regeneration capacity in the scaffolds (Fig. 4C). Noni treated BMSCs led to a significant increase of bone formation $(p<0.05)$ (Fig. 4C). Interestingly, there was also significant increase $(p<0.001)$ (Fig. 4C) in defect area bone density in Noni with BMSCs as compared with BMSC alone.

\section{Discussion}

In this study we observed that Noni could induce osteogenesis of BMSC. Our results demonstrate a novel action of Noni in which osteogenesis of BMSC was promoted through activating the master osteogenic transcription factor Runx2 gene transcription. We first observed that Noni can increase proliferation and promote osteogenesis of BMSC by enhancing the activity of the osteogenic marker ALP and OCN (Fig. 3B). The proliferative effect of Noni may be due to polyphenol contents (22) which promote BMSC proliferation. An earlier report showed that polyphenols block reactive oxygen species production, reduces apoptotic cell death and maintains BMSC cell viability (23).
Runx2 is the early and master transcription factor initiating the osteogenic lineage transcriptional program, which leads to upregulation of various bone-related genes and markers such as ALP and OCN, a bone-formation marker responsive to construct bone matrix (24). The results suggest that Noni induced osteogenesis may be due to controlling the lineage specific transcriptional program on the basis of inducing Runx2. Runx2 have been demonstrated to bind to the osteoblast-specific cis-acting element 2 (OSE2) of the OCN promoter region and regulate OCN expression (25). Hence, it is reasonable to speculate that Noni could have acted in a manner to induce mRNA expression of ALP, OCN and consequently increased Runx2 gene expression in BMSC. Furthermore, flavonoids have also been shown to increase the expression of Runx2 (23). Thus, flavonoids present in Noni might be responsible for the increased expression of Runx2. These results indicate that Noni induces osteoblast differentiation as a function of dose might be due to the presence of flavonoids catechin and epicatechin (26). Recent evidence indicates that flavanols like epigallocatechin and catechin (27) show prominent osteogenic activities both in vitro and in vivo.

Our data demonstrate that the Noni combined with
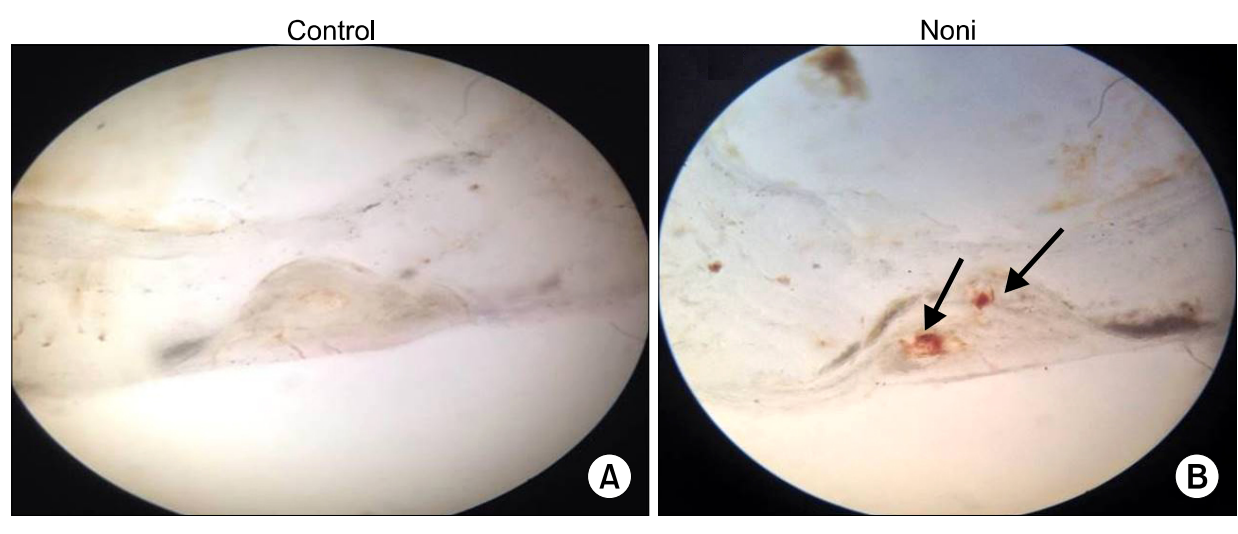

C

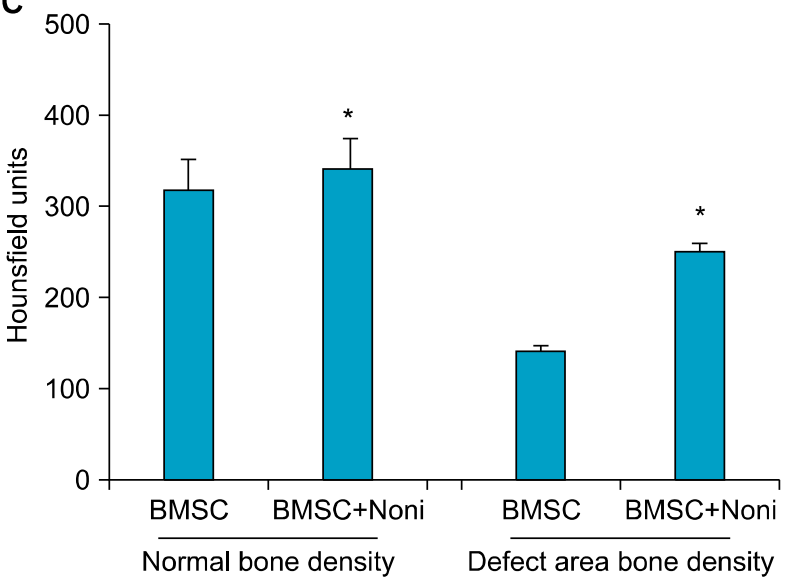

Fig. 4. Histological appearance of bone regeneration by implanting BMSC with Noni $(200 \mu \mathrm{g} / \mathrm{ml})$. Surgical specimens 6 weeks after implantation of (A) Type I collagen with BMSC shows normal bone healing with single harvesian system. (B) Type I collagen with BMSC and Noni, arrow showing neo-vascularization with additional blood vessels and increased bone density. (C) Histogram shown the new bone formation 6 weeks after implantation of type I collagen with BMSC and Noni $(n=6)$. The data are mean $\pm S D$. ${ }^{*} p<0.01$ when compared with type I collagen and BMSC group (BMSC-bone marrow derived mesenchymal stem cells). 
BMSC boosted osteogenesis. Bone healing influenced not only by the BMSC seeded on a scaffold or addition of Noni, but the scaffold itself is a very important component. Collagen, the most abundant protein in the animal body is an excellent and potential biomaterial scaffold for various tissue engineering applications. In biological systems, it provides room for cell attachment, differentiation, regeneration, and repair (28). The enhanced osteogenesis in Noni exposed BMSC, might be caused by alteration of the biological microenvironment. The major problem with cell replacement therapy is the loss of transplanted BMSC at the site of graft. Reactive oxygen species (ROS) and non-specific inflammation generated at the injured site have been found to be the culprit (29). In such an unwanted scenario, Noni's anti-inflammatory (30) and antioxidant (31) activity might be able to protect BMSC and achieve an effective and high-density cell population within three-dimensional biodegradable collagen scaffolds. It has been used for its antibacterial properties and currently there has been studies done on different components of noni which attributes to the specific anti-bacterial property (32). As far as use of Noni for bone regeneration is concerned this anti-bacterial property may have an effect in preventing secondary bacterial infection of the site thereby promoting better wound healing.

Furthermore, Computed tomographic imaging and histological analyses showed more, better quality bone in the femur that received the BMSC exposed to Noni transplant compared with the control femur that received BMSC alone. Noni had a positive effect on vascularization. These results provide pre-clinical evidence that BMSC exposed to Noni transplantation promotes bone regeneration and suggest the approach could be used in a clinical setting to enhance bone regeneration and healing in patients with poor quality bone.

A large number of beneficial effects have been claimed for Noni. Fruit juice of Noni has been approved as a Novel Food by the European Commission in 2003. One article reviewed current knowledge on the phytochemistry, pharmacology, safety aspects of Noni fruit and Noni-derived products, and health-related claims and benefits (33). The knowledge on the chemical composition of Noni fruit has considerably increased over recent years. A number of in vitro and, to a certain extent, in vivo studies demonstrated a range of potentially beneficial effects. One class of active phytochemicals in noni is the iridoids, which has anticancer, antioxidant, anti-inflammatory, and immunomodulating properties (34).

However, as many components of noni juice have been identified which may have beneficial effects (18), the use of noni fruit puree allows the influence of additive and possible synergistic actions of these components versus reductionism to isolated components which are unlikely to have the full benefits of the fruit. Noni juice also contains a small percentage of grape juice (11\%) to enhance palatability and could add or synergize with the noni juice. However, in a clinical trial using grape juice as a placebo, only noni puree resulted in the beneficial reduction of lipid peroxidation and reactive oxygen species (35). Therefore, the small percentage of other juices may not be responsible for the induction of osteogenesis in rat; however, as different outcomes were investigated, these juices may still have a partial role in osteogenesis. This is the first study to show that Noni juice is a promising osteoinductive agent for bone regeneration. To what extent the findings from experimental pharmacological studies are of potential clinical relevance is not clear at present.

Thus, the results from this study suggest that Noni increases proliferation, osteoblast differentiation of BMSC and plays an important role in regeneration of the bone, which indicated that it may be one of the anti-osteoporotic herbal candidate free from side effects. This preliminary in vitro and in vivo work warrants further detailed analysis at cellular and molecular levels to exactly designate Noni for future use in the cure and management of bone metabolism disorders.

\section{Acknowledgments}

The authors are grateful to VIT University, Vellore, Tamilnadu, India for providing financial support for this investigation.

\section{Potential conflict of interest}

The authors have declared that there is no conflict of interest.

\section{References}

1. The United Nations (UN). 2012. Available from: http://www.un.org/en/. Accessed July 2012

2. The World Health Organization (WHO). 2012. Available from: http://www.who.int/en/. Accessed July 2012

3. Woolf $\mathrm{AD}$, Pfleger B. Burden of major musculoskeletal conditions. Bull World Health Organ 2003;81:646-656

4. Scheven BA, Visser JW, Nijweide PJ. In vitro osteoclast generation from different bone marrow fractions, including a highly enriched haematopoietic stem cell population. Nature 1986;321:79-81

5. Long F. Building strong bones: molecular regulation of the osteoblast lineage. Nat Rev Mol Cell Biol 2011;13:27-38

6. Deng S, West BJ, Palu 'K, Jensen CJ. Determination and 
comparative analysis of major iridoids in different parts and cultivation sources of Morinda citrifolia. Phytochem Anal 2011;22:26-30

7. Paredes R, Arriagada G, Cruzat F, Olate J, Van Wijnen A, Lian J, Stein G, Stein J, Montecino M. The Runx2 transcription factor plays a key role in the 1alpha,25-dihydroxy Vitamin D3-dependent upregulation of the rat osteocalcin (OC) gene expression in osteoblastic cells. J Steroid Biochem Mol Biol 2004;89-90:269-271

8. Johnsen SA, Subramaniam M, Ruesink TJ, Spelsberg TC. Opposing roles of osterix and TGF beta inducible early gene in osteoblast differentiation downstream of Cbfal/ Runx2. J Bone Miner Res 2002;17:1016-1019

9. Marom R, Shur I, Solomon R, Benayahu D. Characterization of adhesion and differentiation markers of osteogenic marrow stromal cells. J Cell Physiol 2005;202:41-48

10. Aubin JE. Regulation of osteoblast formation and function. Rev Endocr Metab Disord 2001;2:81-94

11. Bushnell OA, Fukuda M, Makinodian T. The antibacterial properties of some plants found in Hawaii. Pac Sci 1950; 4:167-183

12. Pawlus AD, Su BN, Keller WJ, Kinghorn AD. An anthraquinone with potent quinone reductase-inducing activity and other constituents of the fruits of Morinda citrifolia (noni). J Nat Prod 2005;68:1720-1722

13. Akihisa $\mathrm{T}$, Matsumoto $\mathrm{K}$, Tokuda H, Yasukawa K, Seino K, Nakamoto K, Kuninaga H, Suzuki T, Kimura Y. Anti-inflammatory and potential cancer chemopreventive constituents of the fruits of Morinda citrifolia (Noni). J Nat Prod 2007;70:754-757

14. Alitheen NB, Manaf AA, Yeap SK, Shuhaimi M, Nordin L, Mashitoh AR. Immunomodulatory effects of damnacanthal isolated from roots of Morinda elliptica. Pharm Biol 2010;48:446-452

15. Gupta RK, Patel AK. Do the health claims made for Morinda citrifolia (Noni) harmonize with current scientific knowledge and evaluation of its biological effects. Asian Pac J Cancer Prev 2013;14:4495-4499

16. Wong $\mathrm{YH}$, Abdul Kadir $\mathrm{H}$. Induction of mitochondria-mediated apoptosis in Ca Ski human cervical cancer cells triggered by mollic acid arabinoside isolated from leea indica. Evid Based Complement Alternat Med 2012 doi: 10.1155/2012/684740

17. Gupta RK, Banerjee A, Pathak S, Sharma C, Singh N. Induction of mitochondrial-mediated apoptosis by Morinda citrifolia (Noni) in human cervical cancer cells. Asian Pac J Cancer Prev 2013;14:237-242

18. West BJ, Deng S, Jensen CJ. Nutrient and phytochemical analyses of processed noni puree. Food Res Intern 2011;44:2295-2301

19. Geiger F, Lorenz H, Xu W, Szalay K, Kasten P, Claes L, Augat P, Richter W. VEGF producing bone marrow stromal cells (BMSC) enhance vascularization and resorption of a natural coral bone substitute. Bone 2007;41:516-522

20. Kasten P, Luginbühl R, van Griensven M, Barkhausen T, Krettek C, Bohner M, Bosch U. Comparison of human bone marrow stromal cells seeded on calcium-deficient hydroxyapatite, beta-tricalcium phosphate and demineralized bone matrix. Biomaterials 2003;24:2593-2603

21. Bhargavan B, Gautam AK, Singh D, Kumar A, Chaurasia S, Tyagi AM, Yadav DK, Mishra JS, Singh AB, Sanyal S, Goel A, Maurya R, Chattopadhyay N. Methoxylated isoflavones, cajanin and isoformononetin, have non-estrogenic bone forming effect via differential mitogen activated protein kinase (MAPK) signaling. J Cell Biochem 2009;108: 388-399

22. Bramorski A, Cherem AR, Marmentini CP, Torresani J, Mezadri T, Costa AAS. Total polyphenol content and antioxidant activity of commercial Noni (Morinda citrifolia L.) juice and its components. Braz J Pharm Sci 2010;46:651-656

23. Srivastava S, Bankar R, Roy P. Assessment of the role of flavonoids for inducing osteoblast differentiation in isolated mouse bone marrow derived mesenchymal stem cells. Phytomedicine 2013;20:683-690

24. Deschaseaux F, Sensébé L, Heymann D. Mechanisms of bone repair and regeneration. Trends Mol Med 2009; 15:417-429

25. Ducy P, Karsenty G. Two distinct osteoblast-specific cis-acting elements control expression of a mouse osteocalcin gene. Mol Cell Biol 1995;15:1858-1869

26. Mohd Zin Z, Abdul Hamid A, Osman A, Saari N, Misran A. Isolation and identification of antioxidative compound from fruit of mengkudu (Morinda citrifolia L). Int J Food Prop 2007;10:363-373

27. Chen CH, Ho ML, Chang JK, Hung SH, Wang GJ. Green tea catechin enhances osteogenesis in a bone marrow mesenchymal stem cell line. Osteoporos Int 2005;16:2039-2045

28. Parenteau-Bareil R, Gauvin R, Berthod F. Collagen-based biomaterials for tissue engineering applications. Materials 2010;3:1863-1887

29. Rodrigues M, Turner O, Stolz D, Griffith LG, Wells A. Production of reactive oxygen species by multipotent stromal cells/mesenchymal stem cells upon exposure to fas ligand. Cell Transplant 2012;21:2171-2187

30. Dussossoy E, Brat P, Bony E, Boudard F, Poucheret P, Mertz C, Giaimis J, Michel A. Characterization, anti-oxidative and anti-inflammatory effects of Costa Rican noni juice (Morinda citrifolia L.). J Ethnopharmacol 2011;133: 108-115

31. Serafini MR, Santos RC, Guimarães AG, Dos Santos JP, da Conceicão Santos AD, Alves IA, Gelain DP, de Lima Nogueira PC, Quintans-Júnior LJ, Bonjardim LR, de Souza Araújo AA. Morinda citrifolia Linn leaf extract possesses antioxidant activities and reduces nociceptive behavior and leukocyte migration. J Med Food 2011;14:1159-1166

32. Wang MY, West BJ, Jensen CJ, Nowicki D, Su C, Palu AK, Anderson G. Morinda citrifolia (Noni): a literature review and recent advances in Noni research. Acta Pharmacol Sin 2002;23:1127-1141

33. Potterat O, Hamburger M. Morinda citrifolia (Noni) fruit--phytochemistry, pharmacology, safety. Planta Med 2007;73:191-199 
34. Deng ZL, Sharff KA, Tang N, Song WX, Luo J, Luo X, Chen J, Bennett E, Reid R, Manning D, Xue A, Montag AG, Luu HH, Haydon RC, He TC. Regulation of osteogenic differentiation during skeletal development. Front
Biosci 2008;13:2001-2021

35. Wang MY, Lutfiyya MN, Weidenbacher-Hoper V, Anderson G, Su CX, West BJ. Antioxidant activity of noni juice in heavy smokers. Chem Cent J 2009;3:13-17 